\title{
How Does Exposure to Mass Media affect HIV Testing and HIV-Related Knowledge Among Adolescents? Evidence From Uganda
}

\author{
Miaba Louise Lompo ${ }^{1} \&$ Jean-Louis Bago ${ }^{2}$ \\ ${ }^{1}$ Department of Information and Communication, Laval University, Canada \\ ${ }^{2}$ Department of Economics, Laval University, Canada \\ Correspondence: Miaba Louise Lompo, Department of Information and Communication, Laval University, \\ Canada.
}

Received: June 24, 2018 Accepted: July 22, 2018 Online Published: August 1, 2018

doi:10.5539/gjhs.v10n9p1 URL: https://doi.org/10.5539/gjhs.v10n9p1

\begin{abstract}
Sexual and reproductive health remains one of the greatest challenges in developing countries. In Uganda, adolescents are the most vulnerable group as far as HIV epidemic is concerned. Mass media awareness campaigns play a key role in promoting sexual and reproductive health among adolescents. Using Uganda's 2016 Demographic Health Survey, we examine the causal effect of mass media exposure on the probability of adolescents getting an HIV test and their HIV-related knowledge. Our results suggest that the exposure to mass media increases both adolescents' likelihood to get tested for HIV and their HIV-related knowledge score. In fact, we find that reading newspapers once a week increases the likelihood of an adolescent to test for HIV by 6.29 percentage points. Listening to radio once a week increases the probability to test for HIV by 4.57 percentage points. This effect increases to 6.56 percentage points when the adolescent listens to the radio more than once a week. Watching TV more than once a week increases adolescents' probability to get tested for HIV by 8.57 percentage points. For HIV-related knowledge, we find that compared to adolescents who do not read newspapers at all, adolescents who read newspapers less than once a week and those who read newspapers at least once a week have a higher score of HIV-related knowledge of $9.12 \%$ and $9.64 \%$ respectively. Compared to adolescents who do not listen to radio at all, adolescents who listen to radio less than once a week have a higher (5.88\%) score of HIV related knowledge. Moreover, listening to radio at least once a week increases the score of HIV-related knowledge by $5.52 \%$. Hence, mass media awareness campaigns are important policies to promote HIV testing and HIV-related knowledge among adolescents in Uganda.
\end{abstract}

Keywords: mass media, HIV testing, HIV-related knowledge, adolescents, Uganda

\section{Introduction}

HIV epidemic and related diseases remain the leading causes of preventable mortality among adolescents in sub-Saharan Africa (USAIDS, 2017). Uganda is one of the most affected countries in the world with more than 1.4 million people living with HIV and 28,000 deaths of AIDS-related illnesses in 2016 (USAIDS (2017). Despite increasing efforts to scale up treatment initiatives and to reach 100 percent of HIV testing, the rate HIV testing is still very low in Uganda (Kadede et al., 2016). Recent studies by Idele et al. (2014) and Staveteig et al. (2013) using national survey data across sub-Saharan Africa estimate that more than three quarters of adolescents have never been tested for HIV. In a study in Uganda and Kenya, Kadede et al. (2016) finds that 91\%, 74\%, and 45\% respectively in early (10-14 years old), mid (15-17) and late (18-24) adolescents have never been tested for HIV in Uganda. This causes a serious risk for HIV epidemic spreading among adolescents since knowledge is an important prevention factor for any disease (Kaale and Muhanga, 2017). In addition, the report of USAIDS (2017) reveals a very poor sexual health literacy and knowledge about sexually transmitted infections including HIV among adolescents in Uganda. Kaale and Muhanga (2017) finds that almost a quarter of teenagers still lack basic knowledge on HIV transmissions in Tanzania. To address this public health issue, mass communication plays a key role (Vidanapathirana et al., 2005). In fact, mass media is an important channel to increase an individual's knowledge about sexual health, improve the knowledge of facilities related to HIV prevention and highlight the benefits of HIV testing (Onsomu et al., 2013; Sano et al., 2016). Sano et al. (2016) finds that mass media increases the knowledge of HIV and facilities related to HIV testing and creates a demand for HIV testing. These results are supported by evidence in the literature which reveals that exposure to mass media such as television, radio, and print media affects individuals' risky sexual behaviours (Bertrand \& Anhang, 2006; McCombie et al., 2002). To 
this extent, Uganda, like other sub-Saharan Africa has implemented sensitization policies using mass media to inform and encourage adolescents about sexual health risks (Oronje et al. 2011). Campaigns utilize newspapers, radio and television to reach people in order to increase HIV knowledge, to improve sexual risk perception, to change sexual behaviour, and reduce the effect of stigmatizing attitudes towards HIV testing among adolescents.

Yet, the empirical linkage between mass media and HIV testing remains unclear. Indeed, some previous studies argue that the mass media by addressing general messages or exposing substantial amounts of sexual content can cause harmful influences on adolescents and even promote risky sexual behaviour among adolescents (Brown, 2002; Brown et al., 2006; Brown, et al., 2001; Collins et al., 2004). In contrast, another set of papers find that mass media intervention such as awareness campaigns, because of their reach and effectiveness, can be used as efficient channels to promote sexual health among adolescents (Courbet, 2003; Danmadji et al., 2013; Flay et al., 1980).

Using Uganda's 2016 Demographic Health Survey, this paper examines the effect of mass media on HIV testing among adolescents. We focus on three mass communication channels: print mass media (newspaper), audio mass media (radio) and audiovisual media (television). We analyze the effects of each mass media on HIV testing and HIV-related knowledge. We build a score of HIV-related knowledge representing the number of right answers an adolescent gave to the three questions: (i) Can someone get HIV from mosquito bites? (yes or no), (ii) Can someone get HIV by sharing food with a person who has AIDS? (yes or no); (iii) A healthy-looking person can have HIV? (yes or no).

The findings suggest that the exposure to mass media increases both adolescents' likelihood to test for HIV and their HIV-related knowledge score. The estimates of the effect of mass media on HIV testing suggest that reading newspapers once a week increases the likelihood of an adolescent to test for HIV by 6.29 percentage points. Listening to radio once a week increases the probability to test for HIV by 4.57 percentage points. This effect rises to 6.56 percentage points when the adolescents listen to radio more than once a week. Watching TV more than once a week increases adolescents' probability to test for HIV by 8.57 percentage points. The estimates of the effect of mass media on HIV-related knowledge suggests that, compared to adolescents who do not read newspapers at all, adolescents who do read newspapers less than once a week and those who read newspapers at least once a week have a higher score of HIV-related knowledge of $9.12 \%$ and $9.64 \%$ respectively. Compared to adolescents who do not listen to radio at all, adolescents who listen to radio less than once a week have a higher $(5.88 \%)$ score of HIV knowledge. Moreover, listening to radio at least once a week increases the score of HIV-related knowledge by $5.52 \%$. Overall, our results suggest that the exposure to newspapers and radio increases adolescents' knowledge about HIV transmission. Our results are consistent with findings in the literature which suggest that mass media because of their reach and effectiveness can be used as channels for increasing adolescents' knowledge about HIV and HIV testing behaviour (Courbet, 2003; Danmadji et al., 2013).

The rest of this paper is structured as follows. Section 2 presents the data and methods; Section 3 presents the descriptive statistics. The results are presented in Section 4. Section 5 discusses the results and concludes the paper.

\section{Data and Method}

This section describes the data we use to analyze the effect of an adolescent's exposure to mass media on her/his HIV testing and HIV-related knowledge. It also outlines our empirical method.

\subsection{Data}

We use data from Uganda 2016's Demographic and Health Survey to examine the effect of adolescents' exposure to mass media on HIV testing and HIV-related knowledge. This database contains information about participants' age, gender, level of education, the frequency of exposure to mass Media such as newspapers, radio, and television, their HIV testing status and their knowledge of HIV. Our analysis focuses on two dependent variables: HIV testing, HIV-related knowledge. For HIV testing variable denotes Testing, the respondents were asked whether they have ever been tested for HIV (yes or no). We define the HIV testing variable as a dummy equal 1 if an adolescent self-reported that has ever been tested for HIV and 0 otherwise. For HIV related knowledge, we built a score of knowledge based on the respondent answer to the three following questions: (1) Can someone get HIV from mosquito bites? (yes or no), (2) Can someone get HIV by sharing food with a person who has AIDS? (yes or no); (3) A healthy-looking person can have HIV? (yes or no). The right answer to the first two questions is "No" and the right answer to the last question is "Yes". We define HIV related knowledge as a discrete score equals the number of right answers the respondent gives. So, the score takes values in $S=0,1,2$ or 3 . Our explanatory interest is the exposure to mass media which were captured by three variables. The first one is the frequency of reading print media (newspapers) denoted Newspaper. The second variable is the frequency of listening to radio (denoted Radio) 
and the last variable is the frequency of watching television (denoted $T V$ ). These variables are categorical which take three values: 0 if the participant does not use this media at all, 1 if the frequency of using this media is "less than once a week" and 2 if the frequency of using the media is "at least once a week". We restricted our data to individuals aged between 15 and 19 years old in order to focus on adolescents. The main sample contains 5546 adolescents.

\subsection{Method}

We use multivariate regressions to estimate the effect of mass media (newspaper, radio and TV) exposure on adolescents' sexual health in Uganda focusing on HIV testing and HIV-related knowledge.

\subsubsection{Mass Media and HIV Testing}

Since Testing $g_{i}$ the status of an adolescent $i$ regarding HIV testing is a binary variable, we use a probit regression to estimate the effect of mass media on the probability to test for HIV. Our model is given by the following equation:

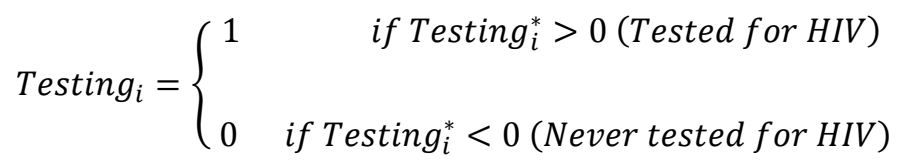

where

$$
\operatorname{Testing~}_{i}^{*}=\alpha_{0}+\sum_{j=1}^{2} \alpha_{j 1} \text { Newspaper }_{j i}+\sum_{j=1}^{2} \alpha_{j 2} \text { Radio }_{j i}+\sum_{j=1}^{2} \alpha_{j 3} T_{j i}+X_{i}^{\prime} \gamma+\varepsilon
$$

Testing $g_{i}^{*}$ is the latent variable which sign determines the HIV testing status and $\varepsilon$ is a zero-mean error term. We include two dummies for each mass media considering the outcome "Not exposed at all" as the base outcome of our regression.

$X_{i}$ includes the adolescent $i$ 's other characteristics such as his/her age, his/her gender, his/her education, his/her household's wealth index and a dummy for residence in his/her place of residence (urban area).

The probability of Testing $g_{i}=1$ can then be written as follows:

$$
\begin{aligned}
P\left(\text { Testing }_{i}=1\right) & =P\left(\text { Testing }_{i}^{*}>0\right) \\
& =P\left(\alpha_{0}+\sum_{j=1}^{2} \alpha_{j 1} \text { Newspaper }_{j i}+\sum_{j=1}^{2} \alpha_{j 2} \text { Radio }_{j i}+\sum_{j=1}^{2} \alpha_{j 3} T V_{j i}+X_{i}^{\prime} \gamma+\varepsilon>0\right) \\
& =P\left(\varepsilon<\alpha_{0}+\sum_{j=1}^{2} \alpha_{j 1} \text { Newspaper }_{j i}+\sum_{j=1}^{2} \alpha_{j 2} \text { Radio }_{j i}+\sum_{j=1}^{2} \alpha_{j 3} T V_{j i}+X_{i}^{\prime} \gamma\right) \\
& =\Phi\left(\alpha_{0}+\sum_{j=1}^{2} \alpha_{j 1} \text { Newspaper }_{j i}+\sum_{j=1}^{2} \alpha_{j 2} \text { Radio }_{j i}+\sum_{j=1}^{2} \alpha_{j 3} T V_{j i}+X_{i}^{\prime} \gamma\right)
\end{aligned}
$$

where $\Phi($.$) is the normal distribution. This probability and the parameters of the model are estimated using a$ maximum likelihood. To deal with the potential clustering of observations at the neighbourhood level, we estimate the model using heteroskedasticity robust standard errors. For our interpretation, we estimate the marginal effect of each mass media on the probability to test for HIV.

\subsubsection{Mass Media and HIV-Related Knowledge}

In this section, we estimate the effect of an adolescent exposure to mass media on the HIV-related knowledge score. The score for HIV-related knowledge $h k s_{i}$ is the number of good answers by an adolescent $i$ (taking values in $H K S=\{0,1,2,3\})$. This score is a discrete variable and then, we use a Poisson regression which is appropriate for count data analysis. The conditional average of the Poisson model denotes $\lambda_{i}$ is written as follows: 


$$
\lambda_{i}=\operatorname{Exp}\left(\beta_{0}+\sum_{j=1}^{2} \beta_{j 1} \text { Newspaper }_{j i}+\sum_{j=1}^{2} \beta_{j 2} \text { Radio }_{j i}+\sum_{j=1}^{2} \beta_{j 3} T V_{j i}+X_{i}^{\prime} \delta+\mu\right)
$$

The likelihood function to be estimate is the following:

$$
\operatorname{Pr}\left(H K S=h s_{i} \mid \text { Newspaper }_{i}, \text { Radio }_{i}, \text { TV }_{i}, X_{i}\right)=\frac{e^{-\lambda_{i}} \lambda_{i}^{h k s_{i}}}{h k s_{i} !}
$$

For our interpretation, we also estimate the marginal effects in order to evaluate the causal effect of adolescents' exposure to each mass media on the HIV-related knowledge score.

\section{Descriptive Statistics}

The summary of descriptive statistics is presented in Table (1). We observe that almost a half (45.9\%) of adolescents have never been tested for HIV in Uganda. This causes a serious risk for HIV epidemic to spread among adolescents. Looking at the score related to HIV knowledge, we observe that less than a half (48.4\%) of adolescents find the right answer to all these three questions. In addition, $34.8 \%$ of them give one wrong answer, $14.85 \%$ give two wrong answers and $2.35 \%$ did not get any right answer to all of the three questions. These statistics suggest that Ugandan adolescents also face an important problem of misconception and lack of knowledge on HIV. As far as exposure to mass media is concerned, the statistics suggest that radio is the most popular media channel among adolescents in Uganda. In fact, more than $55.5 \%$ listen to radio at least once a week while only $9.81 \%$ read newspapers at least once a week and $20.5 \%$ of adolescents have access to television at least once a week. Newspapers are less used than the other types of mass media with almost a third $(74.7 \%)$ of adolescents who do not read newspapers at all. Finally, we observed that around $67 \%$ of adolescents in our sample have a primary education while $30.6 \%$ have a secondary or higher education and females represent $77.1 \%$ of our sample.

\begin{tabular}{|c|c|c|c|c|}
\hline Variables & Mean & Sd & Min & Max \\
\hline HIV testing & 0.541 & 0.498 & 0 & 1 \\
\hline \multicolumn{5}{|c|}{ HIV related Knowledge Score (HKS) } \\
\hline$H K S=0$ & 0.0235 & 0.152 & 0 & 1 \\
\hline$H K S=1$ & 0.145 & 0.352 & 0 & 1 \\
\hline$H K S=2$ & 0.348 & 0.476 & 0 & 1 \\
\hline$H K S=3$ & 0.484 & 0.500 & 0 & 1 \\
\hline \multicolumn{5}{|c|}{ Frequency of exposure to newspapers } \\
\hline Not at all & 0.754 & 0.431 & 0 & 1 \\
\hline Less than once a week & 0.148 & 0.355 & 0 & 1 \\
\hline At least once a week & 0.0981 & 0.297 & 0 & 1 \\
\hline \multicolumn{5}{|l|}{ Exposure to Radio } \\
\hline Not at all & 0.277 & 0.448 & 0 & 1 \\
\hline Less than once a week & 0.168 & 0.373 & 0 & 1 \\
\hline At least once a week & 0.555 & 0.497 & 0 & 1 \\
\hline \multicolumn{5}{|l|}{ Exposure to TV } \\
\hline Not at all & 0.666 & 0.472 & 0 & 1 \\
\hline Less than once a week & 0.129 & 0.336 & 0 & 1 \\
\hline At least once a week & 0.205 & 0.403 & 0 & 1 \\
\hline
\end{tabular}

Table 1. Descriptive Statistics 


\begin{tabular}{|c|c|c|c|c|}
\hline \multicolumn{5}{|l|}{ Education level } \\
\hline No education & 0.0236 & 0.152 & 0 & 1 \\
\hline Primary & 0.670 & 0.470 & 0 & 1 \\
\hline Secondary and more & 0.306 & 0.461 & 0 & 1 \\
\hline \multicolumn{5}{|l|}{ Wealth Index } \\
\hline Poorest & 0.213 & 0.409 & 0 & 1 \\
\hline Poorer & 0.210 & 0.407 & 0 & 1 \\
\hline Middle & 0.192 & 0.394 & 0 & 1 \\
\hline Richer & 0.194 & 0.395 & 0 & 1 \\
\hline Richest & 0.191 & 0.394 & 0 & 1 \\
\hline \multicolumn{5}{|l|}{ Gender } \\
\hline Male & 0.229 & 0.420 & 0 & 1 \\
\hline Female & 0.771 & 0.420 & 0 & 1 \\
\hline \multicolumn{5}{|l|}{ Age } \\
\hline 15 years old & 0.207 & 0.405 & 0 & 1 \\
\hline 16 years old & 0.234 & 0.423 & 0 & 1 \\
\hline 17 years old & 0.185 & 0.388 & 0 & 1 \\
\hline 18 years old & 0.195 & 0.396 & 0 & 1 \\
\hline 19 years old & 0.179 & 0.384 & 0 & 1 \\
\hline \multicolumn{5}{|l|}{ Area of residence } \\
\hline Rural & 0.791 & 0.407 & 0 & 1 \\
\hline Urban & 0.209 & 0.407 & 0 & 1 \\
\hline
\end{tabular}

\section{Results}

First, we analyze the effect of mass media on HIV testing and then, we estimate the effect of mass media on HIV-related knowledge.

\subsection{The Effect of Mass Media on HIV Testing}

Table (2) presents the results of our estimations on the impact of newspapers, radio and TV on HIV testing. The coefficients and the marginal effects $(\mathrm{dy} / \mathrm{dx})$ are presented for each model estimated.

In Model (1), we include only the variables of mass media as a determinant of HIV testing. The results suggest that the exposure to mass media increase adolescents' probability to test for HIV. In fact, compared to adolescents who do not read newspapers at all, the estimated marginal effects (dy/dx) indicate that adolescents who are exposed to newspapers once a week and more than once a week have respectively 9.22 and 6.1 percentage points more probability to test for HIV. Like newspapers, the effect of exposure to radio on HIV testing is also positive and significant. The results suggest that adolescents who are exposed to radio once a week and more than once a week have respectively 4.61 and 8.25 percentage points more probability to test for HIV than those who do not listen to radio at all. Finally, we find that adolescents who are exposed to TV more than once a week have 9.92 percentage points more probability to test for HIV than those who do not watch TV at all.

In Model (2), we control for adolescents' individual characteristics such as age, gender and education. The results suggest that being exposed to newspapers once a week continue to have a positive effect (5.98 percentage points) on the probability to test for HIV. This effect is smaller than the effect obtained in Model (1) but is statistically significant. In addition, being exposed to radio less than once a week or at least once a week also has a positive and significant effect as well as being exposed to TV more than once a week. Moreover, education, age and being a female appears to increase the likelihood of adolescents to test for HIV. This result is consistent with Lompo, Bago and Souratié (2018) who find that education promote sexual healthy behavior among adolescents.

Finally, in Model (3), we control for family level characteristics such as the wealth index and the area of residence. 
The results suggest that reading newspapers once a week increases the likelihood of an adolescent to test for HIV by 6.29 percentage points. Listening to radio once a week increases the probability to test for HIV by 4.57 percentage points. This effect increases to 6.56 percentage points when the adolescents listen to radio more than once a week. Watching TV more than once a week increases adolescents' probability to test for HIV by 8.57 percentage points.

Overall, these results suggest that the exposure to mass media have a positive effect on the likelihood of an adolescent to test for his/her HIV status.

Table 2. Mass media exposure and adolescents' HIV testing

\begin{tabular}{|c|c|c|c|c|c|c|}
\hline \multirow{2}{*}{ VARIABLES } & \multicolumn{2}{|l|}{ Model (1) } & \multicolumn{2}{|l|}{ Model (2) } & \multicolumn{2}{|l|}{ Model (3) } \\
\hline & coeff & $d y / d x$ & coeff & $d y / d x$ & coeff & $d y / d x$ \\
\hline \multicolumn{7}{|l|}{ Exposure to newspaper } \\
\hline \multicolumn{7}{|l|}{ Base $=$ Not at all } \\
\hline \multirow[t]{2}{*}{ Less than once a week } & $0.238 * * *$ & $0.0922 * * *$ & $0.172 * * *$ & $0.0598^{* * *}$ & $0.181 * * *$ & $0.0629 * * *$ \\
\hline & $(0.0507)$ & $(0.0194)$ & $(0.0540)$ & $(0.0187)$ & $(0.0541)$ & $(0.0187)$ \\
\hline \multirow[t]{2}{*}{ At least once a week } & $0.156^{* * *}$ & $0.0610 * * *$ & 0.0829 & 0.0291 & 0.0905 & 0.0316 \\
\hline & $(0.0602)$ & $(0.0233)$ & $(0.0659)$ & $(0.0230)$ & $(0.0660)$ & $(0.0230)$ \\
\hline \multicolumn{7}{|l|}{ Exposure to radio } \\
\hline \multicolumn{7}{|l|}{ Base $=$ Not at all } \\
\hline \multirow[t]{2}{*}{ Less than once a week } & $0.117 * *$ & $0.0461 * *$ & $0.120 * *$ & $0.0424 * *$ & $0.130 * *$ & $0.0457 * *$ \\
\hline & $(0.0535)$ & $(0.0211)$ & $(0.0555)$ & $(0.0195)$ & $(0.0556)$ & $(0.0195)$ \\
\hline \multirow[t]{2}{*}{ At least once a week } & $0.210 * * *$ & $0.0825^{* * *}$ & $0.162 * * *$ & $0.0570 * * *$ & $0.187 * * *$ & $0.0656^{* * *}$ \\
\hline & $(0.0413)$ & $(0.0163)$ & $(0.0434)$ & $(0.0153)$ & $(0.0443)$ & $(0.0156)$ \\
\hline \multicolumn{7}{|l|}{ Exposure to TV } \\
\hline \multicolumn{7}{|l|}{ Base $=$ Not at all } \\
\hline \multirow{2}{*}{ Less than once a week } & 0.0222 & 0.00873 & 0.0307 & 0.0108 & 0.0577 & 0.0203 \\
\hline & $(0.0534)$ & $(0.0210)$ & $(0.0568)$ & $(0.0200)$ & $(0.0576)$ & $(0.0202)$ \\
\hline \multirow[t]{2}{*}{ At least once a week } & $0.256^{* * *}$ & $0.0992 * * *$ & $0.184 * * *$ & $0.0641 * * *$ & $0.247 * * *$ & $0.0857 * * *$ \\
\hline & $(0.0459)$ & $(0.0176)$ & $(0.0498)$ & $(0.0173)$ & $(0.0588)$ & $(0.0202)$ \\
\hline \multirow[t]{2}{*}{$\overline{\text { Age }}$} & & & $0.311 * * *$ & $0.109 * * *$ & $0.310^{* * *}$ & $0.108 * * *$ \\
\hline & & & $(0.0132)$ & $(0.00388)$ & $(0.0132)$ & $(0.00388)$ \\
\hline \multirow[t]{2}{*}{ Female dummy } & & & $0.326^{* * *}$ & $0.114^{* * *}$ & $0.339 * * *$ & $0.118 * * *$ \\
\hline & & & $(0.0436)$ & $(0.0150)$ & $(0.0439)$ & $(0.0150)$ \\
\hline \multicolumn{7}{|l|}{ Education } \\
\hline \multicolumn{7}{|l|}{ (Base $=$ no education $)$} \\
\hline \multirow[t]{2}{*}{ Primary } & & & $0.302 * *$ & $0.107 * * *$ & $0.382 * * *$ & $0.134 * * *$ \\
\hline & & & $(0.118)$ & $(0.0410)$ & $(0.119)$ & $(0.0406)$ \\
\hline \multirow[t]{2}{*}{ Secondary and more } & & & $0.522 * * *$ & $0.184^{* * *}$ & $0.643 * * *$ & $0.226^{* * *}$ \\
\hline & & & $(0.123)$ & $(0.0428)$ & $(0.125)$ & $(0.0428)$ \\
\hline \multirow{2}{*}{\multicolumn{7}{|c|}{$\begin{array}{l}\text { Wealth Index } \\
\text { (Base=Poorest) }\end{array}$}} \\
\hline & & & & & & \\
\hline \multirow[t]{2}{*}{ Poorer } & & & & & $-0.130 * *$ & $-0.0444 * *$ \\
\hline & & & & & $(0.0548)$ & $(0.0187)$ \\
\hline
\end{tabular}




\begin{tabular}{|c|c|c|c|c|c|c|}
\hline Middle & & & & & $-0.208 * * *$ & $-0.0716^{* * *}$ \\
\hline \multirow[t]{2}{*}{ Richer } & & & & & $-0.205^{* * *}$ & $-0.0706^{* * *}$ \\
\hline & & & & & $(0.0594)$ & $(0.0203)$ \\
\hline \multirow[t]{2}{*}{ Richest } & & & & & $-0.237 * * *$ & $-0.0816^{* * *}$ \\
\hline & & & & & $(0.0752)$ & $(0.0256)$ \\
\hline \multirow[t]{2}{*}{ Urban residence } & & & & & 0.00965 & 0.00336 \\
\hline & & & & & $(0.0544)$ & $(0.0189)$ \\
\hline \multirow[t]{2}{*}{ Constant } & $-0.135^{* * *}$ & & $-5.943^{* * *}$ & & $-5.911 * * *$ & \\
\hline & $(0.0326)$ & & $(0.262)$ & & $(0.283)$ & \\
\hline Observations & 5,546 & 5,546 & 5,546 & 5,546 & 5,546 & 5,546 \\
\hline
\end{tabular}

Robust standard errors in parentheses $* * * \mathrm{p}<0.01, * * \mathrm{p}<0.05, * \mathrm{p}<0.1$.

\subsection{Effect of Mass Media on HIV-Related Knowledge}

Table (3) presents the results of the estimations on the impact of newspapers, radio and TV on HIV-related knowledge. As stated in the previous section, we present the coefficients and the marginal effects (dy/dx) for each model estimated.

Model (i) includes only the frequency of exposure to newspapers, radio and TV as determinants of adolescent score of HIV-related knowledge. We find that the exposure to mass media increases adolescents' score of HIV-related knowledge. In fact, compared to adolescents who are not exposed to newspapers at all, reading newspapers less than once a week increases the score of HIV-related knowledge by 19.3 percent. The effect increases to 21.8 percent when the frequency of reading newspapers is up to at least once a week. Moreover, listening to radio less than once a week increases the score related to HIV knowledge by 7.5 percent. While the effect is 8.3 percent for adolescents who listen to radio at least one a week, watching television at least once a week increases adolescents' score of HIV-related knowledge by 12.8 percent.

Model (ii) controls for adolescents' individual characteristics such as age, gender and education level. We find that the exposure to newspapers and radio still have a positive effect on HIV-related knowledge. The effect of reading newspaper less than once a week is reduced to 9.7 percent but is still significant. In fact, the effect is 10.1 percent for adolescents who are exposed to newspapers at least once a week. Moreover, being exposed to radio less once a week increases the HIV-related knowledge score by 6.3 percent and by 5.85 percent if the exposure is at least once a week. We also find that the effect of television on HIV knowledge is not statistically significant anymore.

In Model (iii), we control for family level characteristics such as wealth index and area of residence. The results suggest that, compared to adolescents who do not read newspapers at all, adolescents who read newspapers less than once a week and those who read newspapers at least once a week have a higher score of HIV-related knowledge of $9.12 \%$ and $9.64 \%$ respectively. Compared to adolescents who do not listen to radio at all, adolescents who do listen to radio less than once a week have a higher (5.88\%) score of HIV knowledge. Additionally, listening to radio at least once a week increases the score of HIV-related knowledge by 5.52\%. Overall our results suggest that the exposure to newspapers and radio increases adolescents' knowledge about HIV transmission. 
Table 3. Mass media exposure and adolescents' knowledge about HIV

\begin{tabular}{|c|c|c|c|c|c|c|}
\hline \multirow{2}{*}{ VARIABLES } & \multicolumn{2}{|l|}{ Model (i) } & \multicolumn{2}{|l|}{ Model (ii) } & \multicolumn{2}{|l|}{ Model (iii) } \\
\hline & Coeff & $\mathrm{dy} / \mathrm{dx}$ & coeff & $\mathrm{dy} / \mathrm{dx}$ & coeff & $d y / d x$ \\
\hline \multicolumn{7}{|c|}{ Exposure to Newspapers } \\
\hline \multicolumn{7}{|l|}{ Base $=$ not at all } \\
\hline \multirow[t]{2}{*}{ Less than once a week } & $0.0826 * * *$ & $0.193 * * *$ & $0.0419 * * *$ & $0.0971 * * *$ & $0.0394 * * *$ & $0.0912 * * *$ \\
\hline & $(0.0120)$ & $(0.0288)$ & $(0.0121)$ & $(0.0284)$ & $(0.0121)$ & $(0.0284)$ \\
\hline \multirow[t]{2}{*}{ At least once a week } & $0.0928 * * *$ & $0.218^{* * *}$ & $0.0437 * * *$ & $0.101 * * *$ & $0.0416^{* * *}$ & $0.0964 * * *$ \\
\hline & $(0.0141)$ & $(0.0342)$ & $(0.0141)$ & $(0.0333)$ & $(0.0142)$ & $(0.0334)$ \\
\hline \multicolumn{7}{|l|}{ Exposure to Radio } \\
\hline \multicolumn{7}{|l|}{ Base $=$ not at all } \\
\hline \multirow[t]{2}{*}{ Less than once a week } & $0.0329 * *$ & $0.0748 * *$ & $0.0276^{*}$ & $0.0630^{*}$ & $0.0258 *$ & $0.0588^{*}$ \\
\hline & $(0.0154)$ & $(0.0350)$ & $(0.0153)$ & $(0.0349)$ & $(0.0153)$ & $(0.0349)$ \\
\hline \multirow[t]{2}{*}{ At least once a week } & $0.0366^{* * *}$ & $0.0832 * * *$ & $0.0257 * *$ & $0.0585 * *$ & $0.0242 * *$ & $0.0552 * *$ \\
\hline & $(0.0121)$ & $(0.0272)$ & $(0.0119)$ & $(0.0269)$ & $(0.0120)$ & $(0.0272)$ \\
\hline \multicolumn{7}{|l|}{ Exposure to TV } \\
\hline \multicolumn{7}{|l|}{ Base $=$ not at all } \\
\hline \multirow[t]{2}{*}{ Less than once a week } & 0.00753 & 0.0171 & -0.000849 & -0.00194 & -0.00787 & -0.0180 \\
\hline & $(0.0142)$ & $(0.0324)$ & $(0.0140)$ & $(0.0319)$ & $(0.0143)$ & $(0.0326)$ \\
\hline \multirow[t]{2}{*}{ At least once a week } & $0.0551 * * *$ & $0.128 * * *$ & 0.0176 & 0.0405 & -0.00195 & -0.00446 \\
\hline & $(0.0115)$ & $(0.0270)$ & $(0.0116)$ & $(0.0267)$ & $(0.0138)$ & $(0.0315)$ \\
\hline \multirow[t]{2}{*}{ Age } & & & $0.0133 * * *$ & $0.0305 * * *$ & $0.0137 * * *$ & $0.0314 * * *$ \\
\hline & & & $(0.00339)$ & $(0.00775)$ & $(0.00338)$ & $(0.00775)$ \\
\hline \multirow[t]{2}{*}{ Female dummy } & & & 0.0112 & 0.0256 & 0.00747 & 0.0171 \\
\hline & & & $(0.0110)$ & $(0.0252)$ & $(0.0111)$ & $(0.0255)$ \\
\hline \multicolumn{7}{|l|}{ Education } \\
\hline \multicolumn{7}{|l|}{ Base $=$ no education } \\
\hline \multirow[t]{2}{*}{ Primary } & & & 0.0414 & 0.0890 & 0.0327 & 0.0708 \\
\hline & & & $(0.0366)$ & $(0.0771)$ & $(0.0375)$ & $(0.0797)$ \\
\hline \multirow[t]{2}{*}{ Secondary and more } & & & $0.178 * * *$ & $0.410 * * *$ & $0.162 * * *$ & $0.374 * * *$ \\
\hline & & & $(0.0370)$ & $(0.0786)$ & $(0.0382)$ & $(0.0821)$ \\
\hline \multicolumn{7}{|l|}{ Wealth Index } \\
\hline \multicolumn{7}{|l|}{ Base $=$ Poorest } \\
\hline \multirow[t]{2}{*}{ Poorer } & & & & & 0.0244 & 0.0555 \\
\hline & & & & & $(0.0156)$ & $(0.0355)$ \\
\hline \multirow[t]{2}{*}{ Middle } & & & & & 0.00471 & 0.0106 \\
\hline & & & & & $(0.0161)$ & $(0.0362)$ \\
\hline Richer & & & & & $0.0335^{* *}$ & $0.0766^{* *}$ \\
\hline & & & & & $(0.0158)$ & $(0.0360)$ \\
\hline Richest & & & & & $0.0327^{*}$ & $0.0746^{*}$ \\
\hline & & & & & $(0.0192)$ & $(0.0439)$ \\
\hline
\end{tabular}




\begin{tabular}{|c|c|c|c|c|c|c|}
\hline \multicolumn{5}{|l|}{ Urban dummy } & $0.0230^{*}$ & $0.0527^{*}$ \\
\hline & & & & & $(0.0127)$ & $(0.0290)$ \\
\hline \multirow[t]{2}{*}{ Constant } & $0.768^{* * *}$ & & $0.477 * * *$ & & $0.467 * * *$ & \\
\hline & $(0.00982)$ & & $(0.0705)$ & & $(0.0707)$ & \\
\hline Observations & 5,481 & 5,481 & 5,481 & 5,481 & 5,481 & 5,481 \\
\hline
\end{tabular}

Robust standard errors in parentheses $* * * \mathrm{p}<0.01, * * \mathrm{p}<0.05, * \mathrm{p}<0.1$

\section{Discussion and Conclusion}

This paper examines the relationship between exposure to mass media such as newspapers, radio and TV and adolescents' sexual and reproductive health in Uganda. We analyze the effect of mass media on HIV testing and HIV-related knowledge. We build a score for HIV-related knowledge representing the number of good answers the adolescent gives to the three questions: (1) Can someone get HIV from mosquito bites? (yes or no), (2) Can someone get HIV by sharing food with a person who has AIDS? (yes or no); (3) A healthy-looking person can have HIV? (yes or no).

Overall, our results suggest that the exposure to mass media increases both adolescents' likelihood to test for HIV and their score of HIV knowledge. The estimates of the effect of mass media on HIV testing suggest that reading newspapers once a week increases the likelihood of an adolescent to test for HIV by 6.29 percentage points. Listening to radio once a week increases the probability to test for HIV by 4.57 percentage points. This effect increases to 6.56 percentage points when the adolescents listen to radio more than once a week. Watching TV more than once a week increases adolescents' probability to test for HIV by 8.57 percentage points. The estimates of the effect of mass media on HIV-related knowledge suggests that, compared to adolescents who do not read newspapers at all, adolescents who read newspapers less than once a week and those who read newspapers at least once a week have a higher score of HIV-related knowledge of $9.12 \%$ and $9.64 \%$ respectively. Compared to adolescents who do not listen to radio at all, adolescents who listen to radio less than once a week have a higher (5.88\%) score of HIV knowledge. Moreover, listening to radio at least once a week increases the score of HIV-related knowledge by $5.52 \%$. Overall our results suggest that the exposure to newspapers and radio increases adolescents' knowledge about HIV transmission.

Our results are consistent with the literature which suggests that mass media is important in increasing knowledge about HIV among adolescents (Courbet, 2003; Danmadji et al., 2013). Mass media helps improve sexual health in different ways. Courbet (2003) shows that mass media increases sexual health knowledge through the repetition of the message and warning about high risk sexual behaviours. They also influence HIV testing by acting on the perception of risk and motivating the individual to protect themselves. The reduction of stigma by mass media was also reported to have a positive effect on the probability of being tested for HIV (Danmadji et al., 2013). Other studies have also found that listening to radio improve people's sexual health knowledge (Barrere, 1998; Danmadji et al., 2013; Savariaud, 2004). According to our results, mass communication channels such as newspapers, radio and TV are important tools to promote healthy sexual behaviour among adolescents in Uganda.

However, these results raise an interesting question which is not addressed in this paper: what is the influence of new growing social media on adolescents' sexual health behaviour and knowledge in developing countries? An interesting direction for future research will be to analyze the effect new media (internet) and social media on adolescents' sexual and reproductive health in developing countries.

\section{Competing Interests Statement}

The authors declare that there are no competing or potential conflicts of interest.

\section{References}

Barrere, M. (1998). Sexually transmitted diseases and AIDS. https://www.popline.org/node/523124

Bertrand, J. T., \& Anhang, R. (2006). The effectiveness of mass media in changing HIV/AIDS-related behaviour among young people in developing countries. Technical Report Series-World Health Organization, 938, 205.

Brown, J. D. (2002). Mass media influences on sexuality. Journal of sex research, 39(1), 42-45. https://doi.org/10.1080/00224490209552118

Brown, J. D., L'Engle, K. L., Pardun, C. J., Guo, G., Kenneavy, K., \& Jackson, C. (2006). Sexy media matter: exposure to sexual content in music, movies, television, and magazines predicts black and white adolescents' sexual behavior. Pediatrics, 117(4), 1018-1027. https://doi.org/10.1542/peds.2005-1406 
Brown, J. D., Steele, J. R., \& Walsh-Childers, K. (2001). Sexual teens, sexual media: Investigating media's influence on adolescent sexuality: Routledge.

Collins, R. L., Elliott, M. N., Berry, S. H., Kanouse, D. E., Kunkel, D., Hunter, S. B., \& Miu, A. (2004). Watching sex on television predicts adolescent initiation of sexual behavior. Pediatrics, 114(3), e280-e289. https://doi.org/10.1542/peds.2003-1065-L

Courbet, D. (2003). Réception des campagnes de communication de santé publique et efficacité des messages suscitant de la peur. Une étude expérimentale sur le rôle de la peur dans le changement des attitudes néfastes. Communication. Information médias théories pratiques, 22(1), 100-120. https://doi.org/10.4000/communication.4786

Danmadji, N. L., Nadjioroum, N. G.-A., \& Tonalta, F. (2013). Prévalence du VIH/SIDA en milieu scolaire de Sarh: cas des élèves des établissements secondaires dépistés au Centre de Santé de Maïngara. Revue Scientifique du TCHAD, 1(3), 61-66.

Flay, B. R., DiTecco, D., \& Schlegel, R. P. (1980). Mass media in health promotion: An analysis using an extended information-processing model. Health education quarterly, $7(2), \quad$ 127-147. https://doi.org/10.1177/109019818000700203

Idele, P., Gillespie, A., Porth, T., Suzuki, C., Mahy, M., Kasedde, S., \& Luo, C. (2014). Epidemiology of HIV and AIDS among adolescents: current status, inequities, and data gaps. JAIDS Journal of Acquired Immune Deficiency Syndromes, 66, S144-S153. https://doi.org/10.1097/QAI.0000000000000176

Kaale, G., \& Muhanga, M. (2017). Sexual health knowledge among secondary school students in Morogoro, Tanzania: half full or full empty?. International Journal of Health, 5(2), 120-125. https://doi.org/10.14419/ijh.v5i2.8190

Kadede, K., Ruel, T., Kabami, J., Ssemmondo, E., Sang, N., Kwarisiima, D., . . Clark, T. D. (2016). Increased adolescent HIV testing with a hybrid mobile strategy in Uganda and Kenya. AIDS (London, England), 30(14), 2121. https://doi.org/10.1097/QAD.0000000000001180

Lompo, M. L., Bago, J. L., Souratié, W. M (2018) Estimating the Impact of School Education on Contraception Use among Adolescents Aged 15-19 in Burkina Faso and Nigeria: Evidence from a Heckman Two-Step Correction Model, Journal of Education and Learning 7 (5), 31-42. https://doi.org/10.5539/jel.v7n5p31

McCombie, S., Hornik, R. C., \& Anarfi, J. (2002). Effects of a mass media campaign to prevent AIDS among young people in Ghana. Public health communication: Evidence for behavior change, 147-162.

Onsomu, E. O., Moore, D., Abuya, B. A., Valentine, P., \& Duren-Winfield, V. (2013). Importance of the media in scaling-up HIV testing in Kenya. SAGE Open, 3(3), 2158244013497721. https://doi.org/10.1177/2158244013497721

Oronje, R. N., Undie, C. C., Zulu, E. M., \& Crichton, J. (2011). Engaging media in communicating research on sexual and reproductive health and rights in sub-Saharan Africa: experiences and lessons learned. Health Research Policy and Systems, 9(1), S7. https://doi.org/10.1186/1478-4505-9-S1-S7

Sano, Y., Sedziafa, A. P., Amoyaw, J. A., Boateng, G. O., Kuuire, V. Z., Boamah, S., \& Kwon, E. (2016). Exploring the linkage between exposure to mass media and HIV testing among married women and men in Ghana. AIDS care, 28(6), 684-688. https://doi.org/10.1080/09540121.2015.1131970

Savariaud, S. (2004). Staying alive in Senegal. Global AIDSLink, (86), 10-11.

Staveteig, S., Wang, S., Head, S., Bradley, S., \& Nybro, E. (2013). DHS Comparative Reports No. 30. Calverton, Maryland, USA: ICF International.

Unaids (2017) Data retrieved from http://www.unaids.org/sites/default/files/media_asset/20170720_Data_ book_2017_en.pdf

Vidanapathirana, J., Abramson, M. J., Forbes, A., \& Fairley, C. (2005). Mass media interventions for promoting HIV testing. The Cochrane Library. https://doi.org/10.1002/14651858.CD004775.pub2

\section{Copyrights}

Copyright for this article is retained by the author(s), with first publication rights granted to the journal.

This is an open-access article distributed under the terms and conditions of the Creative Commons Attribution license (http://creativecommons.org/licenses/by/4.0/). 